World Lumen Congress 2021 | May 26-30, 2021 |

Iasi, Romania

\title{
Aesthetics and Creativity. Identity Configurations
}

\author{
Livia DURAC
}

https://doi.org/10.18662/wlc2021/21

How to cite: Durac, L. (2021). Aesthetics and Creativity. Identity Configurations. In A. Sandu (vol. ed.), Lumen Proceedings: Vol. 17 World Lumen Congress 2021 (pp. 198-208). Iasi, Romania: LUMEN Publishing House. https://doi.org/10.18662/wlc2021/21 


\title{
Aesthetics and Creativity. Identity Configurations
}

\author{
Livia DURAC 1
}

\begin{abstract}
Reflecting on human attitude towards reality, together with deciphering the emotional code that accompanies it, has configured - in time - the aesthetic universe, open to human reflection, creation, and evaluation. Aesthetics appears through the way in which consciousness reacts and capitalises upon things in nature and society, or which belong to buman subjectivity, including on artistic work, which have an effect on sensitiveness due to their harmony, balance and grandeur. As a fundamental attribute of the buman being, creativity is the engine of cultural evolution, meaning the degree of novelty that man brings in bis ideas, actions, and creations. Aesthetical values, together with the other types of values, contribute to what society represents and to what it can become, hence motivating human action and creation. Their role is to create a state of mind that encourages the cohesion, cooperation, and mutual understanding of the society. Integrating a chronological succession of the evolution of the concepts that objectify its structure, its aesthetics and creativity, this article stresses the synergetic nature of the two dimensions of human personality, paving the way to beauty, as a form of enchantment of the human spirit.
\end{abstract}

Keywords: Arts, aesthetics, creativity, society.

\section{Benchmark in the configuration of aestetics}

Approaches to the aesthetic universe consider the forms of manifestation of human presence in which the conscience of the first existential meanings and senses was shaped in time, configuring forms of material and spiritual culture. The experience of the various aspects of reality was expressed through gestures and attitudes, through symbolic constructions, through rituals and play. All these have brought a specific testimony on the spiritual and practical life of a community, respectively on the order that preserves solidarity and the process of life.

The specialised form of aesthetics is expressed through art. In their beginning, aesthetic manifestations were tightly related to the other human activities. In Antiquity, for instance, human consciousness was working in full syncretism, with no distinction between arts, crafts, or sciences; we can note that the term "art" (techne) used to englobe, in Antiquity, multiple practical and knowledge-related meanings. The gradual process of understanding and differentiation of the artistic activity finds its expression in the changes that occur within ancient society, in the mentality and consciousness of that time, and in the

\footnotetext{
${ }^{1}$ Professor PhD, ’Petre Andrei” University of Iaşi, Romania. E-mail: liviadurac@yahoo.com
} 
new needs for expression.

From the perspective of mythological knowledge, the aspect of differentiating between arts is marked, for example, by the museums that inspired and protected them. Thus, if in the beginning Apollo was seen as the protector of poetry, music, and dance, in time each art will have its own muse. Clio became the muse of history, Thalia the muse of comedy, Calliope - the muse of epic poetry, Euterpe, the muse of lyrical poetry, Terpsichore - of dance, Melpomene - of tragedy, Erato - of rhetoric poetry, and Urania, of astronomy.

Based on the presented information, an idea is formed on the way of understanding and classifying arts from the perspective of mythological consciousness. According to this viewpoint, in ancient classification, the scope of so-called musical arts (poetry, music, and dance) also included a series of sciences, such as astronomy and architecture, while those related to crafts and plastic arts, such as painting, sculpting, and architecture, were a separate category. At a mythological level, this distinction is expressed through the relationship between Apollo and Hephaestus, the former being the protector of musical arts and the latter, of technical arts, meaning those linked to crafts and plastic arts. In time, the connections between the two categories of arts started to be taken into account more and more. Thus, Simonides of Keos believed that dance is muted poetry, and painting is talking poetry; on the other hand, Democritus sees the unity between crafts, architecture, and music in the act of imitation.

Lato will make the distinction between imitative arts and crafts; in the Greek philosopher's opinion, the former imitate imitation, while crafts imitate ideas seen as archetypes. Aristotle speaks of musical arts (music and poetry) versus plastic arts (sculpture, architecture); he also makes the distinction between poetry and history, respectively between poetry and philosophy, while approaching the nature of imitation in art. In the same order of ideas, we must also mention the opinion of Dionysus of Halicarnassus (1st century BC), according to whom the purpose of art is beauty and, in general, aesthetics; he mainly referred to poetry, prose, sculpture, and painting.

If in Antiquity, the accent fell on the distinction between musical arts and technical arts, in the medieval ages this difference is mainly expressed through the opposition between free arts and mechanical arts. Seneca, for instance, in his work "Letters to Lucilius" divides arts into two categories: free versus mechanical, or non-free. The category of free arts included the following: grammar, rhetoric, geometry, music, and poetry. Mechanical arts included all the others, such as painting, sculpture, etc. This vision of the arts was, nevertheless, contradictory; thus, on the one hand, art was seen as a way for the people's consciousness to comprehend the connection between man and divinity; however, there was a danger to focus on the hedonistic dimension to the detriment of the moral one. On the other hand, issues existed in understanding art as mimesis, starting from the idea that God is pure spirit, therefore He cannot be imitated.

In St. Augustin's opinion, plastic arts are seen as inferior to church music and architecture, since man is too attached to objects and too remote from divinity. From 
the perspective of this meaning, plastic arts can only find their place in the world of symbols and allegory. In the Middle Ages as well, the opposition between free and mechanical arts continues to exist; this time, the category of free arts included: grammar, rhetoric, dialectics, arithmetic, music, geometry, and astronomy. The first three made up a trivium, while the other four made up a quadrium. We must notice that free arts, which were seen more as theoretical disciplines, did not include poetry. As for mechanical arts, they included all the crafts as well as plastic arts.

The Renaissance era brings new perspectives, broadening the scope of free arts by including among them all types of plastic creations; this period also marks a reconciliation between plastic and musical arts. In the spirit of medieval tradition, during Renaissance, we can still witness the accent placed on the confrontation between arts, whose purpose is to enhance the superiority of one art in relation to another. The division of art by genre and style is, nevertheless, the result of late antique thinking when, for example, discussions about rhetoric mention high, medium, and humble styles. Generally, the issue of style will take an important place in Cicero's and Quintilian's works, but also in Michelangelo's and Dante Alighieri's thinking. The last author will state: "for tragedy we use a higher style, for comedy a more humble one, for elegy we prefer the speech of the unfortunate"(Kagan, 1979).

The modern era brings new coordinates for the understanding of aesthetics and art in general. Marked by complex social changes, the modern era opens the way to new sensibilities, where the criterion of reason takes an important place. The transition towards modernity seems most obvious at the level of aesthetics, which is considered "the most eloquent area where the new world starts to distance itself artistically from the old one" (Munteanu, 1981).

In the order of approaches that explain aesthetics, we must mention Leibinz's contribution, who, in his work "De cognitione, veritate et ideis" (1784), speaking of the four steps of knowledge, believes that aesthetics and aesthetic perception are part of the second step of knowledge, which is at the same time clear and confuse, imaginative but not intellectual. In the German thinker's opinion, this "I don't know what" (nescio quid) that generates sympathy is the main feature of aesthetic perception. But the theoretician who tried to separate the limits of aesthetics, managing to subject the universe of sensitiveness and feelings to a deep logical analysis, was Alexander Gottlieb Baumgarten. Using for the first time the term of "aesthetics", Baumgarten defines the new discipline as "the science of sensorial knowledge" (Ferry, 1997). This opens a new horizon for reflection and interpretation - the horizon of sensitiveness, which has its own logic where beauty is understood as a form of manifestation of perfection.

Aesthetics and its categories know, in modern times, new horizons of meanings, given by the socio-economic, axiological, and scientific mutations that characterize our age. If all the values that society promotes meet the conditions and requirements to function normally, in our times when rhythm is accelerated, when time weighs more than ever on the existential side of things, aesthetics and its unchanged world are a benchmark for perfection and delight of the senses, meant to ensure the balance of the spirit in this world of transition and deceit. 


\section{Aestetical values}

Aesthetic was configured, in time, through the analysis of the characteristic aspects linked to the manifestation of human attitudes towards the various hypostases of reality, embodied by objects and processes that occur in nature, in society, or that belong to consciousness; the area of significance of aesthetics, in its specialised form, also includes artistic creations. The objects towards which human attitude and appreciation is directed generally stand out through a series of features such as harmony, balance, symmetry, perfection, etc. This attitude through which people become sensitive to the mentioned aspects forms the contents of aesthetic attitude.

Speaking of aesthetics, G.W.F. Hegel says: "its object is the widespread sharing of beauty; more precisely: its field is art, in particular fine arts" (Hegel, 1966). In the history of aesthetic thinking, for a long time, aesthetics was considered to be a synonym of beauty; for this reason, discussions and reflections in the field have also aimed to clarify these two categories. At present, it is considered that aesthetics is a very general category, while beauty is a specific one, together with ugliness, tragedy, comedy, etc.

Aesthetic judgment includes, in itself, two hypostases: judgment of taste and judgment of value. According to Immanuel Kant, the basis of the judgment of taste lies in the free play of knowledge abilities, meaning in the relationship between intellect and imagination. Aesthetic judgment varies according to several factors; in this sense, we must mention Kant's idea that "the beautiful is what pleases everyone." Value judgment is different from existential judgment. While the nature of the latter is linked to observation, value judgment is a statement in which the logical dimension intermingles with the axiological one. If the act of creation generates the work, in receiving and appreciating it, the important role is played by value judgment.

Speaking of aesthetic values, it is necessary to make the distinction between aesthetic and artistic; thus, if the notion of "aesthetics" is broad and with a vast scope, the notion of "artistic" is specialised. The distinction and interference lines between aesthetic and artistic represent the background on which the process of renewal and experimentation in the aesthetic world took place. The term "beautiful" also has different meanings; the history of aesthetic thought reveals that, in time, several versions of beauty were configured: a classical one that imposed certain rules, and another one that implied complete freedom. We could also see that beauty defines art, but it is present outside of it as well - for example in nature, society, and daily life.

If art is a "specialised field of aesthetic value" (Ianoşi, 1978), beauty, as an aesthetic value, operates with a vast scope since it is an attribute of human sensitiveness that makes us give a sense and meaning to human constructions, relations or realities. Artistic value is the result of the creation process, but its meaning comes in the process of reception and appreciation. Artistic value belongs to the work of art as a whole set of meanings, as a world that functions according to the logic of truthfulness. Allowing themselves to be seen from the perspective of different 
currents, styles, branches, or genres, artistic values are of great diversity. Through the action of appreciation, these values accede to the cultural reality of time.

The beauty of human creations, besides artistic creations per se, also includes useful goods, which can be industrial products and which, besides their functionality, have an aesthetic value. Architectonic constructions are also an example where the functional nature significantly intertwines with the artistic one. Similarly, design has a practical side as well as an aesthetic side. The unity between the functional, useful, and artistic components built together the meaning of the concept of urban planning. The scope of aesthetics and the efficiency of the concept of beauty are realities that exist in the area of that world of human subjectivity where intentionality and meaning play a determining role. This explains the power of the symbol and of the symbolic medium that articulates the shape of a culture and civilisation, and it also helps deciphering the foundations of the philosophical ideas that appeared through time.

Aesthetics and its categories know new horizons of significance in relation with the socio-economic, axiological, and scientific mutations of the period that humankind is living. First of all, we can notice an increasing need for certainty and beauty, of justice and truth, which should motivate human action and sensitiveness. The angle from which consciousness opens to the world of aesthetics is one of birth and support for the meaning, a force that stems from the absolute nature of consciousness and which marks, in its entirety, the destiny of humankind. The changes that occur in society and the inherent difficulties that accompany them generate negative phenomena in social life, where truth and justice prove to be unable to institute order, motivating human action.

There exists a syncretic manifestation of values within society, where truth is good and beauty. For example, the dysfunctions in a transitioning society essentially affect human relationships by generating uncertainty, unsafety, as well as passivity towards these phenomena. In such a context, the main cause for all this is the lack of interest from the political class in leading in agreement with elementary moral norms and with the law. The lack of interest and will to act correctly can be - and most often is - completed by an insatiable thirst to become rich, accompanied by arrogance towards real human values. Thus, the values followed by the political class only support their own personal interests, in an obvious opposition with the real values of society, in spite of these laws and regulations being clearly stipulated.

Such framing in reality is seen by civil society as a great evil, while in the collective psychology it generates apathy and high expectations with regards to a "cleansing" of the political class, in such a way that change would be reflected in the citizen's life standards. In this context we can speak of ugliness in social life, a concept that refers to a deformed reality, degraded from the meanings it should have, a tough reality that is difficult to accept. Literature and arts in general capitalize nevertheless upon these life issues, since beauty is enhanced in opposition with ugliness, but at the level the public's axiological consciousness, the reception of ugliness - seen as the degradation of man, as an infringement of the norm, therefore as a lack of meaning leads to revolt and despair. This is one hypostasis of the existential script that 
philosophical thinking approached assiduously, in an attempt to sensitise consciousness towards the difficult problems in need of a solution.

\section{Creativity. General considerations}

As a fundamental attribute of the human being, creativity means the degree of novelty that man brings in his ideas, actions, and creations. Concerns to understand this phenomenon have existed since ancient times; thus, in pre-Christian thinking the idea of genius took shape, which, in the perspective of that time, meant a positive protecting spiritual force. For ancient Greeks, this protective spirit was an individual's daimon. The biblical legend of creation presented in the Genesis is the oldest and most significant conception of creation. However, this vision was replaced after the 2 nd century BC by the doctrine proposed by Saint Augustin in his work "City of God". The idea around which this doctrine is built is that of the role played by Christianity in revealing man's power to create.

The idea of creation as an action that imitates ideal forms characterises Plato's vision on the purpose of art. A particular impulse in understanding creation is brought by Renaissance, an era when the issues of imagination, of individual liberties, and of the autonomy of society in human relations were born.

"For almost the entire Renaissance era and during the numerous philosophical debates that took place, scientific works have become known for their ability to reveal and destabilise cultural and religious paradigms" (Sternberg, 2005). In this respect, we must mention the influence of the works by Copernicus, Galileo, and Newton, which allowed for a new understanding of the analysed realities. The 17 th century brings a new vision on reason and the individual, as natural sciences become institutionalised philosophies and methodologies; the changes in paradigm confirmed another type of freedom for the individual, respectively his right to freely explore reality and his own universe. For the 18th century world, it was important to find answers for deciphering the limits of the freedom of thought and to identify its meaning at a social and political level. These questions then further allowed searching for answers on the nature of creativity and practicing it. At the same time, it was possible to establish the distinction between the concept of creativity and that of genius, originality, talent, and formal education (Pană, 2000). We can say that the defining feature of the whole existence is creativity, where nevertheless novelty is rare, an aspect also mentioned by Fr. Iacob in his work Logic of the living. Creativity is also regarded from a general standpoint by M. Drăgănescu, the author considering it to be a structural component of existence, just like information. In his vision, there is an agreement between the creativity of the universe and that of the human being and of society. The same pattern of thinking characterises the ideas of H. Bergson who, in his work "Creative evolution", supports the idea that the essence of live processes is creativity, which is also the very meaning of existence.

In Romanian culture, the idea of value and creation takes an important place in Lucian Blaga's philosophical vision, which argues that man's destiny is to create and that the result of creation is building an artificial world. 


\section{Perspectives in studying creativity}

Creativity has been studied with various means and from different perspectives. In the beginning, in the 50's, a pragmatic approach on freedom was predominant, with a main accent on its development and less on the way of testing the validity of ideas. This moment is marked by the contribution of Edward De Bono, who completes his interest in the practical aspects of creativity with studies on lateral thinking; Osborn develops and uses the brainstorming technique and Gordon resorts to synectics, which implies analogies.

In the last century, creativity was studied under a psychodynamic approach. Psychology schools such as structuralism, functionalism and behaviourism were not concerned with studying creativity. Only gestalt focused its interest on one of the aspects of creativity: insight. We must nevertheless mention that studies were only concerned with identifying insight, not with characterising this phenomenon.

Psychometric approaches have represented, to an equal extent, an important direction in analysing human creativity. In essence, the psychometric approach uses the creativity measuring technique, building up into a source of information for understanding the phenomenon of creativity. Investigations on creativity were initiated, anthropometric models were applied to the study of imagination and intelligence, using imagination and inventiveness tests, as well as divergent thinking tests.

The specific fields of psychometric research are: investigating the creative process, the personality factors and the behavioural links of creativity, of the features of the creative products and of the environment that stimulates creativity (Munteanu, 1981).

Psychometric researches bring light on the phenomenon of creativity by quantifying the creative processes via the use of evaluation tests. In this context, the higher ratio belongs to the category of tests that analyse divergent thinking, with a large applicability in schools. The importance of this type of tests is explained as follows: "divergent thinking tests require the individual to generate more reactions to a specific stimulus, contrary to most performance and skill-based standardised tests that require one single correct answer." (Ferry, 1997).

A synthetic presentation of the various categories of studies referring to creativity includes psychometric, experimental, biographic, historiometric, and biometric tests. Between these categories we can notice intertwining and similarities; the psychometric approach, through its interest placed on studying the dependency on cognitive factors, is closer to biometric studies; analysing the connections between the cerebral functions and the types of cognitive activity is the object of the biometric approach to creativity. This approach consists in "monitoring the metabolism of cerebral carbohydrates in an individual while he executes cognitive tasks (for example, while solving mathematical problems), because the metabolism of carbohydrates is one of the variables that express cerebral activity; thus, researchers can identify and evaluate activity in specific areas of the brain, since each area is involved in the cognitive activity; this is in fact a neuromeric approach"(Hegel, 1966). 
Experimental research is concerned with studying the correlation between the following variables: personality, creativity, creative processes and products. In the historiometric approach, measuring creativity is an operation applied to selected data coming from various historic documents. This method was used by Simonton in studying the correlation between creativity and leadership, invention and discovery, creativity and age, musical creativity and excellence. The biographic approach is also called "case study" and it involves applying the methodology of qualitative research in reference to the situations taken into account.

\section{Systemic vision on creativity}

Researches on the phenomenon of creativity have proven its complex nature, the fact that it is determined from a mental, psychological, as well as social perspective. As a result, in explaining creativity, besides the personal thoughts, emotions, and motivations that create and produce original things, public and social recognition take an important place. As mentioned in specialised literature, "creativity is a process that can be seen at the intersection between person, field, and speciality" (Ianoşi, 1978).

In Mihaly Csikszentmihaly's opinion, the environment has two aspects: the culturally symbolic one, which here we call "field", and the social one, called "specialty". In this vision, "creativity is manifested when someone causes a change in a certain field, and this change is further transmitted in time. Some people have a better chance to generate such changes because of their personal skills or because they are lucky enough to be in a favorable position in relation to that field - they have a better access to it or their social position allows them more time to experiment"(Sternberg, 2005).

In understanding the phenomenon of creativity, the concept of system and the systems method have an important place. It is considered that the "systems model is analogous to the one used by scientists to describe the process of evolution. Evolution occurs when an individual's body creates a variation, which is selected by the environment and transmitted to future generations." From this perspective, "creativity can be regarded as a special case of evolution; in particular, it is, for cultural evolution, what mutation, selection, and the transmission of genetic variations are for biological evolution."(Sternberg, 2005).

The act of creativity causes a change in the system of symbols of a culture, a change that also affects the thoughts and feelings of the members of the respective culture; "creativity implies modifying the "memes", the units of imitation, that Dawkins (1976) calls "the bricks of culture" (Sternberg, 2005).

Memes are like genes in the way that they carry in themselves the working instructions. The notes of a song show how it should be sung, the recipe for a cake indicates the ingredients and baking time. But while genetic instructions are transmitted through the chemical codes inherited in the chromosomes, the instructions included in memes are transmitted through learning. In general, memes are learned and reproduced without any modification; new songs or recipes are 
based on creativity.

Cultures are systems of interrelated fields, such as music, mathematics, religion, various technologies, etc., areas where innovation also occurs. "Cultures differ from one another through the way they store memes, respectively the technical procedures, types of knowledge, art styles, and systems of beliefs (Sternberg, 2005). However, "the appearance of new means of storage and transmission (for example, books or computers) will influence the production rate of original works and their acceptation.’'(Sternberg, 2005).

The accessibility of information is a dimension of cultural differences. Since cultures differ from one another through the number of fields they acknowledge and through their hierarchy, the attraction of a specific field will depend on several variables. Aspects such as storing information, its accessibility and availability, their degree of differentiation in that specific culture, how integrated the culture is, as well as its degree of openness to other cultures, are all taken into account. New memes appear in cultures that are exposed to diverse ideas and beliefs, but two other situations are also possible:

(a) when the symbolic system is poorly integrated, it becomes difficult to establish if a new thing is a real contribution, truly enriching a certain field (for example, the period before Mendeleev);

(b) in the opposite situation, when the system is too strict, innovation is no longer possible - as was the case for physics at the end of the 19th century, before the revolution generated by quantum theory.

In the evolution of a culture, two interdependent processes are at work respectively, the process of integration and that of differentiation. Trough integration, the fields in a culture become inter-articulated, mutually supporting their objectives. Creativity is the engine of cultural evolution, favoring differentiation and developing new fields that become gradually more autonomous. We can thus draw the conclusion that, in order to create something new and original, the individual contribution of the creator is as much needed as the evaluation made by society, since "in science as well as in art, creativity is to an equal extent the result of the modification of standards and of the appearance of new evaluation criteria, and of individual original achievements."(Sternberg, 2005). Creativity gives an impulse to the evolution of society, a process translated through progress as well as through increased complexity in time. Societies differ from one another according to the way they relate to innovation, and respectively to the way they evaluate and support it. In general, the creativity ratio is influenced by differentiation and integration processes. A culture's creativity is influenced by the interdependence between its fields and by what happens at the level of each of them.

\section{Factors that structure creativity}

From the series of factors that structure the phenomenon of creativity, we can mention intelligence (the highest ranking in this hierarchy), imagination, special skills, intuition, effort, motivations, attitudes, and temper. Besides intelligence, 
effort (especially continuous one) generates creativity; an illustrative example in this sense is given by Edison, according to whom talent is 1\% inspiration and $99 \%$ perspiration. Talent, or special skills, also play an important place in creation. In any effective human activity, both general and special skills are involved. Being a special skill, talent manifests itself in performing a specific activity and in a specific field, such as science, technics, art, music, literature, etc. One's interest for a certain activity absolutely conditions the process of shaping and development of his/her own personal skills.

From a psychological perspective, imagination is considered to be man's ability to invent. Specialised literature shows that "we can define imagination as a psychological process of occurrence of mental, imaginary, or ideational constructions, tending to create newness based on perceptive experience and on the given intellectual training, with its contents being both what is real and what is possible, what is present and what is future" (Pană, 2000).

G. H. Lehman directed his attention mainly towards analysing imagination in relation with creativity in science and, at the same time, with experience and age. In his opinion, imagination in science includes three dimensions: extension, expressiveness, and productivity. In what concerns extension and expressiveness, imagination varies from one individual to another, expressiveness being particularly important in physics and especially in plastic arts. The productivity of imagination can be measured through the number and importance of the applications of imagination processes. However, high productivity means low originality. Imagination implies several functions, of which the most important are the representation of possible actions and the fact that it helps formulating hypotheses that can be tested through later checks.

Charles Pierce, in his work "Significance and action", shows the grounded connection between the real world and that of imagination, of which we can say that, in the context of modernity, is enhanced by the recent progresses in creating virtual reality. The factors that accompany the act of creation includes intuition, which has received several meanings, such as: way of knowledge, method of knowledge or non-mediated knowledge, in the idea that newness is deciphered directly, omitting some stages of scientific reasoning.

\section{Conclusion}

The reflections in time on aesthetics reflect a specific reaction and attitude towards the significant aspects of reality and founds itself on aesthetic judgment. The latter expresses, at a theoretical level, one's attitude and ability to receive, respectively to appreciate the effect of an aesthetic value on his/her own conscience. Aesthetic judgment combines the interpretation dimension with appreciation from a specific axiological context, taking into account currents, genres, species, stylistic means, etc. The axiological nature of judgment is given by specific and general criteria.

Evaluation criteria refer to the way in which the creator's intention has been 
achieved in his/her work, in its balance and unity, to the stylistic context and especially to its expressiveness and suggestiveness. The way in which the idealness of art and its power of signification are articulated take an important place.

Based on these statements, we can conclude that the existence of aesthetics stems from the generic life of the human being, regarded in all its ways of manifestation. In this sense, we can speak of several types of beauty: that related to the human being from a bodily, spiritual, behavioural perspective, etc.

\section{References}

Ferry, L. (1997). Homo aestheticus. Minerva Publishing House.

Hegel, G. W. F. (1966). Prelegeri de estetică.( Vol. 1) [Aesthetic lectures]. Academia Română Publishing House.

Ianoşi, I. (1978). Estetica [Aesthetics]. Didactic and Pedagogical Publishing House.

Kagan, M.S. (1979). Morfologia artei [The Morphology of Art]. Meridiane Publishing House.

Munteanu, R. (1981). Cultura europeană in epoca luminilor European Culture in the Age of Enlightenment]. Minerva Publishing House.

Pană, L. (2000). Filosofia culturii tehnice [Philosophy of technical culture]. Technical Publishing House.

Sternberg, R. J. (Ed.). (2005). Manual de creativitate [Creativity Handbook] (I. Mihailescu \& D. L. Ilin, Trans.). Polirom Publishing House. (Original work published 1998) 